\title{
COMPETITIVIDADE DA PRODUÇÃO DE CELULOSE EM DIFERENTES ESTADOS DO BRASIL
}

\author{
Naisy Silva Soares ${ }^{1}$, Márcio Lopes da Silva², José Luiz Pereira de Rezende ${ }^{3}$, \\ Laércio Antônio Gonçalves Jacovine², Sebastião Renato Valverde²
}

(recebido: 20 de dezembro de 2010; aceito: 25 de janeiro de 2013)

RESUMO: No presente trabalho, objetivou-se analisar a competitividade da produção de celulose de fibra curta nos estados de Minas Gerais, São Paulo, Espírito Santo e Bahia, em maio de 2008, utilizando a Matriz de Análise Política (MAP). Os resultados obtidos indicaram que as lucratividades privada e social da produção e comercialização da celulose foram positivas e maiores na Bahia. As empresas brasileiras foram penalizadas por políticas públicas adotadas para o setor. A produção de celulose em São Paulo e Bahia foi mais competitiva e menos exposta aos efeitos negativos das políticas públicas. E, as empresas nacionais tiveram seus lucros reduzidos.

Palavras-chave: Lucratividade, matriz de análise política, economia florestal.

\section{COMPETITIVENESS OF WOOD PULP PRODUCTION IN DIFFERENT BRAZILIAN STATES}

ABSTRACT: This work aimed to analyze the competitiveness of wood pulp production in different Brazilian states, in May, 2008 (Minas Gerais, São Paulo, Espirito Santo and Bahia), using the Policy Analysis Matrix (PAM). The results obtained indicated that the private and social profitability of wood pulp production and commercialization was positive and greater in Bahia. The Brazilian companies were penalized by public policies adopted for the sector; the wood pulp production in São Paulo and Bahia were more competitive and less exposed to the negative effects of public policies that reduce the national company profits.

Key words: Profitability, policy analysis matrix, forest economy.

\section{INTRODUÇÃO}

O segmento de celulose e papel é de grande importância para a economia brasileira. Em 2012, esse segmento gerou 115 mil empregos diretos (68 mil nas indústrias e 47 mil nas florestas) e 575 mil indiretos. Além disso, pagou R $\$ 2,2$ bilhões em impostos e exportou US\$ 5,8 bilhões (ASSOCIAÇÃO BRASILEIRA DE CELULOSE E PAPEL - BRACELPA, 2012).

Em 2010, a produção nacional de celulose foi de 14 milhões de toneladas, sendo, São Paulo (31\%), Bahia (20\%) e Espírito Santo (19\%) e Minas Gerais (11\%). As exportações somaram cerca de 8 milhões de toneladas e as importações, 412 mil toneladas. No caso do papel, a produção brasileira foi cerca de 9 milhões de toneladas, as exportações foram de, aproximadamente, 2 milhões de toneladas e as importações de 1,5 milhões de toneladas, também em 2010 (BRACELPA, 2012).

O segmento brasileiro de celulose e papel apresenta grande potencial de crescimento, pois as empresas brasileiras são competitivas e eficientes, em razão da alta produtividade dos reflorestamentos, em razão das condições climáticas favoráveis à atividade florestal no país, possibilitando ciclos de crescimento rápido e de alta qualidade, e ao baixo custo de produção em relação aos outros países. Acrescenta-se a isso a aceitação da celulose brasileira de fibra curta no mercado internacional, em razão da sua alta qualidade (CARVALHO et al., 2009, 2010; MEDEIROS; FONTES, 1994; SOARES et al., 2007; VALVERDE et al., 2006).

Todavia, o segmento de celulose e papel no país enfrenta a concorrência internacional e a falta de políticas internas adequadas ao seu desenvolvimento.

Nesse sentido, estudos mostrando os efeitos das políticas públicas na produção da celulose são de grande importância para o desenvolvimento do setor no país, pois permitem identificar pontos de estrangulamento na estrutura de custos do setor produtivo, para que se possam direcionar políticas que objetivem a manutenção e, ou, sua ampliação da capacidade produtiva e de exportação de celulose e papel do Brasil. Além disso, podem explicar os impactos de políticas públicas no setor, o que subsidiaria a adoção de medidas políticas que poderiam contribuir para a tomada de decisão

\footnotetext{
${ }^{1}$ Economista, Professora Doutora em Ciência Florestal - Universidade Estadual de Santa Cruz/UESC - Departamento de Ciências Econômicas Campus Soane Nazaré de Andrade - Rodovia Ilhéus-Itabuna km 16 - 45662-900 - Ilhéus, BA, Brasil - naisysilva@yahoo.com.br ${ }^{2}$ Engenheiro Florestal, Professor Doutor em Ciência Florestal - Universidade Federal de Viçosa/UFV - Departamento de Engenharia Florestal Avenida Peter Henry Rolfs, s/n - Campus Universitário - 36570-000 - Viçosa, MG, Brasil - marlosil@ufv.br, jacovine@ufv.br, valverde@ufv.br ${ }^{3}$ Engenheiro Florestal, Professor Doutor em Economia Florestal - Universidade Federal de Lavras/UFLA - Departamento de Ciências Florestais Cx. P. 3037 - 37.200-000 - Lavras, MG, Brasil -jlprezen@dcf.ufla.br
}

Cerne, Lavras, v. 19, n. 2, p. 297-305, abr./jun. 2013 
sobre alocação dos recursos e para a comercialização da celulose.

Nesse contexto, no presente trabalho, objetivouse analisar a competitividade da produção de celulose de fibra curta nos estados de Minas Gerais, São Paulo, Espírito Santo e Bahia. Especificamente, pretendeu-se determinar a lucratividade privada e social da produção de celulose no Brasil para diferentes estados; identificar os efeitos de políticas públicas sobre os diferentes estados em relação ao mercado externo; mensurar os indicadores que avaliam nao grau de competitividade do setor produtivo, a eficiência econômica e os efeitos das políticas neste segmento.

\section{MATERIAL E MÉTODOS}

\subsection{Matriz de Análise Política}

O instrumental utilizado foi da Matriz de Análise Política (MAP), de Monke e Pearson (1989) (Tabela 1), que, no Brasil e na área florestal, foi utilizada no estudo de Rosado et al. (2006) e Sousa et al. (2009a, 2009b).

Os valores a preço privado apresentados na MAP referem-se aos valores no mercado interno. Já, os valores a preços sociais referem-se aos valores no mercado internacional.

A manipulação dos valores contidos na MAP dá origem aos indicadores a seguir.

a) Lucro Privado (D)

O lucro privado é representado pela diferença $\mathrm{A}$ menos B menos C e expressa o lucro obtido a preços de mercado ou a preços privados (equação 1). Como valores praticados no mercado, eles sofrem interferências dos governos na forma de tributos ou subsídios.

$\mathrm{D}=\mathrm{A}-\mathrm{B}-\mathrm{C}$

em que: $A=p^{d} q^{d}$

$$
\begin{aligned}
& \mathrm{B}=\sum_{i=1}^{\mathrm{n}} \mathrm{p}_{\mathrm{i}}^{\mathrm{d}} \mathrm{q}_{\mathrm{i}}^{\mathrm{d}} \\
& \mathrm{C}=\sum_{j=1}^{\mathrm{n}} \mathrm{w}_{j}^{\mathrm{d}} \mathrm{l}_{\mathrm{j}}^{\mathrm{d}}
\end{aligned}
$$

$\mathrm{A}=$ receita privada, $\mathrm{B}=$ custo dos insumos comercializáveis, $\mathrm{C}=$ custo dos insumos domésticos, $\mathrm{p}^{\mathrm{d}}$ $=$ preço privado do produto, $\mathrm{q}^{\mathrm{d}}=$ quantidade total privada de determinado produto, $\mathrm{p}_{i}{ }^{\mathrm{d}}=$ preço privado do insumo $i$, $\mathrm{q}_{\mathrm{i}}^{\mathrm{d}}=$ quantidade privada do insumo i utilizado na produção do bem considerado, $\mathrm{w}_{\mathrm{j}}{ }^{\mathrm{d}}=$ preço privado do insumo $\mathrm{j}$ e $\mathrm{l}_{\mathrm{j}}^{\mathrm{d}}=$ quantidade privada do insumo $\mathrm{j}$ utilizado. Sendo que os indicadores privados referem-se ao mercado interno.

$\mathrm{O}$ cálculo da lucratividade privada informa a competitividade da cadeia produtiva. Se os lucros privados forem negativos $(\mathrm{D}<0)$, os operadores estarão obtendo taxa de retorno subnormal. Por outro lado, se os lucros privados forem positivos $(\mathrm{D}>0)$, os operadores estarão obtendo taxa de retorno sobrenormais, indicando que pode ocorrer expansão do sistema de produção em análise. $\mathrm{O}$ lucro normal ocorre para $\mathrm{D}=0$ (ROSADO et al., 2006).

b) Lucro Social $(\mathrm{H})$

O lucro alcançado a preços sociais é dado por $\mathrm{E}$ menos $F$ menos G (equação 2).

$\mathrm{H}=\mathrm{E}-\mathrm{F}-\mathrm{G}$

em que: $E=p^{s} q^{s}$

$$
\begin{aligned}
& \mathrm{F}=\sum_{i=1}^{\mathrm{n}} \mathrm{p}_{i}^{\mathrm{s}} \mathrm{q}_{\mathrm{i}}^{\mathrm{s}} \\
& \mathrm{G}=\sum_{j=1}^{\mathrm{n}} \mathrm{w}_{j}^{\mathrm{s}} 1_{j}^{\mathrm{s}}
\end{aligned}
$$

Tabela 1 - Matriz de Análise Política (MAP).

Table 1 - Policy analysis matrix (PAM).

\begin{tabular}{lccccc}
\hline \multirow{2}{*}{ Itens } & \multirow{2}{*}{ Receitas } & \multicolumn{2}{c}{ Custos } & Lucros \\
\cline { 3 - 5 } & & Insumos comercializáveis & Fatores domésticos & C & D \\
\hline Preços Privados & $\mathrm{A}$ & $\mathrm{B}$ & $\mathrm{G}$ & $\mathrm{H}$ \\
Preços Sociais & $\mathrm{E}$ & $\mathrm{F}$ & $\mathrm{K}$ & $\mathrm{L}$ \\
Efeitos de divergências e eficiência política & $\mathrm{I}$ & $\mathrm{J}$ & & $\mathrm{K}$ \\
\hline
\end{tabular}

Fonte: Monke e Pearson (1989)

Cerne, Lavras, v. 19, n. 2, p. 297-305, abr./jun. 2013 
$\mathrm{E}=$ receita social, $\mathrm{F}=$ custo dos insumos comercializáveis, $\mathrm{G}=$ custo dos insumos domésticos, $\mathrm{p}^{\mathrm{s}}$ $=$ preço social do produto, $\mathrm{q}^{\mathrm{s}}=$ quantidade total do produto, $p_{i}^{s}=$ preço social do insumo $i, q_{i}^{s}=$ quantidade do insumo $i$ utilizado, $\mathrm{w}_{\mathrm{j}}^{\mathrm{s}}=$ preço social do insumo $\mathrm{j}$ e $\mathrm{l}_{\mathrm{j}}^{\mathrm{s}}=$ quantidade do insumo $\mathrm{j}$ utilizado. Sendo que os indicadores sociais referem-se ao mercado externo.

Esses valores não sofrem interferências do governo brasileiro. Assim, são considerados valores sociais ou econômicos e medem a eficiência do sistema de produção. Como medida de eficiência ou vantagem comparativa, o lucro social, quando negativo, indica que o sistema não é considerado economicamente viável no contexto de mercado internacional, sem assistência do governo. Tem-se uma indicação de que tal sistema não assegura a alocação economicamente eficiente de recursos escassos, dado que produz a custos sociais superiores aos custos de importação (ALVES, 2002; VIEIRA et al., 2001).

c) Efeitos das Divergências e da eficiência política

São analisadas as diferenças entre as avaliações privadas e sociais de receitas, custos e lucros que devem ser explicadas pelos efeitos da distorção política ou pelas imperfeições nos mercados de produtos e fatores (equações (3), (4), (5) e (6)).

Transferência de receitas: $\mathrm{I}=\mathrm{A}-\mathrm{E}$

Transferência de insumos: J = B - F

Transferência de fatores: $\mathrm{K}=\mathrm{C}-\mathrm{G}$

Transferência líquida: $\mathrm{L}=\mathrm{D}$ - H ou L = I - J - K

As transferências de receitas estão associadas à produção e as transferências de insumos estão associadas aos custos de insumos comercializáveis que resultam de políticas que causam divergências entre os preços domésticos dos produtos e os preços internacionais, como políticas específicas de produtos (taxas ou subsídios) e política cambial. Por fim, as falhas de mercado podem também influenciar os preços dos produtos e de fatores. As transferências líquidas combinam efeitos de políticas "distorcivas" com aqueles de falhas de mercado de fator e políticas eficientes para compensá-los (ALVES, 2002).

A comparação entre sistemas de produção foi feita pelos indicadores a seguir apresentados (FERREIRA NETO, 2005; ROSADO et al., 2006): a) Razão Custo Privado (RCP)

A RCP mostra quanto o sistema pode produzir para pagar pelos fatores domésticos, permanecendo competitivo, ou seja, equilibrando a receita com a despesa (sem lucro nem perda), após alcançar lucros normais. Para que o produtor alcance esse objetivo, é necessário que os custos dos fatores domésticos sejam menores que seus valores adicionais (diferença entre receita e custos dos insumos comercializáveis), a preços privados. Desse modo, para a maximização dos lucros, é indispensável a minimização dessa razão por meio do controle dos custos dos fatores domésticos. Essa razão é calculada como apresentado na equação (7).

\section{$\mathrm{RCP}=\mathrm{C} /(\mathrm{A}-\mathrm{B})$}

A RCP pode indicar se os fatores domésticos estão recebendo o seu retorno normal $(\mathrm{RCP}=1)$, acima do retorno normal $(\mathrm{RCP}<1)$ ou abaixo do retorno normal $(\mathrm{RCP}>1)$.

b) Custo dos Recursos Domésticos (CRD)

O Custo dos Recursos Domésticos (CRD) indica o comportamento da lucratividade social, ou seja, quanto se despende de recursos domésticos em valores sociais para gerar uma unidade de divisas por meio da exportação (equação 8).

$\mathrm{CRD}=\mathrm{G} /(\mathrm{E}-\mathrm{F})$

Minimizar o CRD é o equivalente a maximizar os lucros sociais. $\mathrm{O} C \mathrm{CRD}<1$ indica que estaria sendo utilizado menos de um dólar de recursos domésticos para gerar um dólar de divisas e vice-versa. Indica, também, eficiência da produção.

c) Coeficiente de Proteção Nominal (CPN)

O Coeficiente de Proteção Nominal (CPN) indica o impacto da política que provoca divergências entre preços privados e sociais. É a razão entre os preços privados e sociais (equação 9) (FERREIRA NETO, 2005).

$\mathrm{CPNi}=\mathrm{A} / \mathrm{E}$

Tem-se o CPN sobre produtos comercializáveis (CPNp) e sobre os insumos comercializáveis (CNPi) (equação 10 e 11, respectivamente).

$\mathrm{CPNp}=\mathrm{A} / \mathrm{E}$

$\mathrm{CPNi}=\mathrm{B} / \mathrm{F}$

Cerne, Lavras, v. 19, n. 2, p. 297-305, abr./jun. 2013 
Um CPNp > 1 indica que existe transferência de renda da sociedade para os produtores e vice-versa, e um CPNi $>1$ indica transferência de renda negativa aos produtores, pois os custos dos insumos comercializáveis são aumentados pela política e vice-versa (ROSADO et al., 2006).

d) Coeficiente de Proteção Efetiva (CPE)

O Coeficiente de Proteção Efetiva (CPE) permite indicar a extensão dos incentivos ou do desestímulo que os sistemas produtivos recebem das políticas de preços de produtos e de insumos comercializáveis. Se $\mathrm{CPE}>1$, tem-se que o efeito líquido das políticas contribui para um aumento do lucro privado e vice-versa. O CPE é obtido por meio da relação entre diferenças de receitas e custos comercializáveis (equação 12) (ROSADO et al., 2006).

$\mathrm{CPE}=(\mathrm{A}-\mathrm{B}) /(\mathrm{E}-\mathrm{F})$

e) Coeficiente de Lucratividade (CL)

O Coeficiente de Lucratividade (CL) mede o efeito dos incentivos de todas as políticas (equação 13) (FERREIRA NETO, 2005).

$\mathrm{CL}=(\mathrm{A}-\mathrm{B}-\mathrm{C}) /(\mathrm{E}-\mathrm{F}-\mathrm{G})=\mathrm{D} / \mathrm{H}$

f) Taxa de Subsídios aos Produtores (TSP)

A Taxa de Subsídios aos Produtores (TSP) mostra a proporção de renda, em valores sociais, que seria requerida para manter a eficiência econômica se um subsídio ou imposto fosse substituído por um conjunto de políticas, de outra natureza. É uma medida da transferência líquida de políticas (L) como uma proporção das receitas sociais totais (E) (equação 14). Quanto menor a TSP, menos distorcido será o sistema (FERREIRA NETO, 2005).

$\mathrm{TSP}=\mathrm{L} / \mathrm{E}=(\mathrm{D}-\mathrm{H}) / \mathrm{E}$

\subsection{Fonte de dados}

Os preços privados da celulose em Minas Gerais, São Paulo, Espírito Santo e Bahia foram aqueles praticados pelas empresas Cenibra, Votorantin Celulose e Papel, Aracruz Celulose e Veracel (ARACRUZ CELULOSE, 2009; CELULOSE NIPO BRASILEIRA - CENIBRA, 2009; VERACEL CELULOSE, 2009; VOTORANTIN CELULOSE E PAPEL, 2009).

Os custos envolvidos na produção da celulose foram divididos nas seguintes categorias: produção da madeira, produtos químicos, energia, transporte, depreciação, juros e administração.

Cerne, Lavras, v. 19, n. 2, p. 297-305, abr./jun. 2013
Os preços privados da madeira em Minas Gerais foram obtidos no Anuário... (2008). Em São Paulo, os preços da madeira também foram obtidos no Anuário... (2008) e Instituto de Economia Agrícola - IEA (2008). No Espírito Santo, esses preços foram do Centro de Desenvolvimento do Agronegócio - CEDAGRO (2008). $\mathrm{Na}$ Bahia, os preços privados dos insumos comercializáveis e dos fatores de produção foram fornecidos pela Bahia Sul Celulose.

Os preços privados da energia, transporte, depreciação, juros, administração e produtos químicos são do Brasil e estão na média de cada Estado considerado e foram obtidos em Celulose e Papel (1995).

Os preços privados dos insumos comercializáveis e dos fatores domésticos, assim como o preço privado da celulose, foram atualizados para valores de maio de 2008, de acordo com o índice de preços IGP-DI da Fundação Getúlio Vargas (IPEA, 2008).

Com relação aos preços sociais dos insumos comercializáveis e dos fatores de produção, foram obtidos em Baier e Pérramon (2008), Food and Agriculture Organization of the United Nations - FAO (2009) e Silva (1996). Esses preços referem-se aos praticados no Chile e nos Estados Unidos, visto que o Chile também se destaca na produção de celulose de fibra curta e Estados Unidos, há muitos anos, se destaca como o maior produtor e exportador mundial de celulose de todos os tipos (FAO, 2009).

Os preços sociais dos insumos e o valor social do produto são os próprios preços internacionais. Esses preços foram internalizados no Brasil, multiplicando os mesmos pela taxa de câmbio. Posteriormente, foram atualizados para valores de maio de 2008, de acordo com o índice de preços IGP-DI da Fundação Getúlio Vargas (IPEA, 2008).

Ressalta-se que todos os preços considerados estão em R \$ por tonelada de maio de 2008. E, para o cálculo dos custos de produção da madeira, adotou-se um horizonte temporal de 7 anos. Esses custos, foram multiplicados por 4, porque para produzir uma tonelada de celulose são utilizados, em média, $4 \mathrm{~m}^{3}$ da madeira de eucalipto.

\section{RESULTADOS E DISCUSSÃO}

\subsection{Lucratividades privadas e sociais}

Na Tabela 2, são apresentados os resultados da MAP para a produção da celulose de fibra curta em Minas Gerais, São Paulo, Bahia e Espírito Santo, em maio de 2008. 
Tabela 2 - Matriz de Análise Política para a produção da celulose de fibra curta.

Table 2 - Policy Analysis Matrix for wood pulp production.

\begin{tabular}{|c|c|c|c|c|}
\hline \multirow[b]{2}{*}{ Estados } & \multirow{2}{*}{$\begin{array}{c}\text { Receita } \\
(\mathrm{R} \$ / \mathrm{t})\end{array}$} & \multicolumn{2}{|c|}{ Custos de Comercialização (R\$/t) } & \multirow{2}{*}{$\begin{array}{c}\text { Lucro/ } \\
\text { Benefícios Socia } \\
(\mathrm{R} \$ / \mathrm{t})\end{array}$} \\
\hline & & Insumos Comercializáveis & Fatores Domésticos & \\
\hline \multicolumn{5}{|l|}{ Minas Gerais } \\
\hline Preços Privados & $1.301,32$ & 162,26 & $1.051,03$ & 88,03 \\
\hline Valorações Sociais & $1.370,00$ & 235,35 & 998,59 & 136,06 \\
\hline Efeitos de Divergências & $-68,68$ & $-72,99$ & 52,44 & $-48,03$ \\
\hline \multicolumn{5}{|l|}{ São Paulo } \\
\hline Preços Privados & $1.320,00$ & 159,37 & $1.037,72$ & 122,91 \\
\hline Valorações Sociais & $1.370,00$ & 235,35 & 971,96 & 162,69 \\
\hline Efeitos de Divergências & $-50,00$ & $-75,98$ & 65,76 & $-39,57$ \\
\hline \multicolumn{5}{|l|}{ Espírito Santo } \\
\hline Preços Privados & $1.334,40$ & 153,92 & $1.054,23$ & 126,25 \\
\hline Valorações Sociais & $1.370,00$ & 226,60 & 994,45 & 148,95 \\
\hline Efeitos de Divergências & $-35,60$ & $-72,68$ & 59,78 & $-22,70$ \\
\hline \multicolumn{5}{|l|}{ Bahia } \\
\hline Preços Privados & $1.320,30$ & 154,63 & $1.012,59$ & 153,08 \\
\hline Valorações Sociais & $1.370,00$ & 231,47 & 983,64 & 154,89 \\
\hline Efeitos de Divergências & $-49,70$ & $-76,84$ & 28,95 & $-1,81$ \\
\hline
\end{tabular}

Fonte: Dados da pesquisa.

Os resultados obtidos evidenciam que a lucratividade privada da produção e comercialização da celulose para o mercado interno foi positiva para todos os estados, com valores de $\mathrm{R} \$ 88,03, \mathrm{R} \$ 122,91, \mathrm{R} \$ 126,25$ e $\mathrm{R} \$ 153,08$ por tonelada, em Minas Gerais, São Paulo, Espírito Santo e Bahia, respectivamente (Tabela 2). A lucratividade privada foi positiva para a produção de celulose nas quatro regiões, indicando, em termos relativos, a competitividade dos sistemas do ponto de vista privado. Além disso, esses resultados evidenciam que as regiões estudadas ganharam uma taxa de retorno sobrenormal e apresentaram perspectivas favoráveis para o desenvolvimento da produção de celulose, especificamente para exportação.

Em termos comparativos, a produção da celulose de fibra curta na Bahia apresentou maior lucratividade privada, o que indica a maior competitividade desse sistema produtivo. Isso pode ser resultado do menor custo dos fatores domésticos a preço privado e da menor carga tributária paga pelas empresas nesse Estado.

Apesar de a carga tributária em São Paulo ser a mais elevada em comparação com Minas Gerais, Espírito
Santo e Bahia, a produção da celulose no Estado apresentou considerável lucratividade privada, em comparação com Minas Gerais. Esse resultado pode ter sido influenciado pelo fato de São Paulo apresentar o segundo menor custo dos fatores domésticos a preço privado. Espírito Santo apresentou a segunda maior lucratividade privada, pois esse Estado contou com a maior receita a preços privados e o segundo menor custo dos insumos comercializáveis (Tabela 2).

As lucratividades sociais da produção da celulose em Minas Gerais, São Paulo, Espírito Santo e Bahia foram da ordem de $\mathrm{R} \$ 136,06, \mathrm{R} \$ 162,69, \mathrm{R} \$ 148,95$ e $\mathrm{R} \$ 154,89$ por tonelada, respectivamente (Tabela 2). Essa lucratividade social positiva indica que há eficiência econômica na produção de celulose nos quatro Estados, e que eles são eficientes na geração de divisas e alocação de recursos nacionais. Assim, as empresas são incentivadas a produzir.

A maior lucratividade social foi observada em São Paulo, indicando a maior eficiência da produção nesse Estado, em razão dos menores custos de produção.

$\mathrm{O}$ que se observa são lucros privados inferiores aos sociais, na produção da celulose em todos os Estados

Cerne, Lavras, v. 19, n. 2, p. 297-305, abr./jun. 2013 
analisados, resultado que pode ser atribuído à ineficiência de políticas públicas implementadas, ou seja, à ineficiência das políticas públicas na tributação, legislação, taxa de câmbio, taxa de juros, nos encargos sociais e nas políticas comerciais, assim como nas falhas de mercado (concentração do mercado, por exemplo).

\subsection{Transferências financeiras associadas ao preço do produto}

Os resultados da MAP para a produção da celulose mostraram que os preços privados são menores que os preços sociais, ou seja, os preços internacionais, o que evidencia uma transferência negativa de $\mathrm{R} \$ 68,68$, $\mathrm{R} \$ 50,00, \mathrm{R} \$ 35,60$ e $\mathrm{R} \$ 49,70$ por tonelada de celulose em Minas Gerais, São Paulo, Espírito Santo e Bahia, respectivamente (Tabela 2).

Diante desses resultados, pode-se inferir que os empresários brasileiros foram penalizados por políticas distorcivas de juros, política cambial, tributária e comercial, dado que essa atividade recebeu menos do que receberia, se essas políticas não tivessem sido implantadas. Em outras palavras, as empresas de Minas Gerais, São Paulo, Espírito Santo e Bahia poderiam ter alcançado níveis maiores de lucratividade, caso não tivessem sido penalizadas por políticas distorcivas. Mas, mesmo assim, verifica-se que os sistemas são lucrativos (Tabela 2).

O maior valor negativo foi encontrado para Minas Gerais, pois, nesse Estado foi observado o menor preço privado, comparado ao preço verificado nos demais Estados. Mais especificamente, a produção da celulose nos Estados sob análise foi penalizada por taxa de juros e carga tributária elevadas, além de taxa de câmbio desfavorável.

\subsection{Transferências financeiras associadas a preços dos insumos}

Os valores encontrados para as transferências associadas aos custos dos insumos comercializáveis foram negativos, da ordem de $\mathrm{R} \$ 72,99, \mathrm{R} \$ 75,98, \mathrm{R} \$ 72,68$ e R $\$ 76,84$ por tonelada em Minas Gerais, São Paulo, Espírito Santo e Bahia, respectivamente. A explicação para esse fato é que os preços dos insumos comercializáveis, em Minas Gerais, São Paulo, Espírito Santo e Bahia, se situaram abaixo dos internacionais em $45 \%, 48 \%, 47 \%$ e $50 \%$, respectivamente (Tabela 2 ).

Como se trata de insumos comercializáveis, podese dizer que os efeitos de divergências entre os valores privados e sociais são atribuídos ao menor custo dos produtos químicos e da mão de obra no Brasil. Para se ter uma ideia, os custos com produtos químicos e da mão de obra no país foram, respectivamente, $80 \%$ e $55 \%$, menores que no exterior, em maio de 2008. Esse fato parece ter eliminado o impacto negativo da taxação sobre os produtos comercializáveis.

Além disso, a disparidade entre custos privados e sociais foi menor em Minas Gerais e Espírito Santo, indicando que esses Estados possuem as melhores condições de preço para importar insumos, possibilitandolhes aumentar mais seus níveis de produção e rentabilidade. Também, se pode inferir que as políticas vigentes no período tiveram efeitos negativos menores em Minas Gerais e no Espírito Santo.

Quanto às transferências associadas aos fatores domésticos, em Minas Gerais, São Paulo, Espírito Santo e Bahia, foram da ordem de $\mathrm{R} \$ 52,44, \mathrm{R} \$ 65,76, \mathrm{R} \$ 59,78$ e R $\$ 28,95$, por tonelada de celulose. As empresas de Minas Gerais, São Paulo, Espírito Santo e Bahia pagaram, respectivamente, $\mathrm{R} \$ 52,45, \mathrm{R} \$ 65,76, \mathrm{R} \$ 59,78$ e $\mathrm{R} \$ 28,95$, a mais por tonelada de celulose produzida.

Valores positivos para as transferências associadas aos fatores domésticos foram observados, uma vez que os custos privados são maiores que os custos sociais dos fatores domésticos. Em outras palavras, representam uma transferência negativa para o setor produtivo, uma vez que contribuíram para a redução do lucro privado.

Pode-se dizer que o elevado custo privado dos juros, depreciação e transporte foram os que mais contribuíram para esse resultado. No Brasil, os custos com juros, depreciação e transporte foram, respectivamente, $67 \%, 8 \%$ e $21 \%$, maiores que no exterior, em maio de 2008 .

Acredita-se, assim, que a redução na taxa de juros e dos custos portuários favoreceria a competitividade da celulose brasileira no mercado internacional.

Bahia apresentou o menor valor de transferência associada aos fatores domésticos, o que indica menor divergência entre custos privados e sociais desses fatores e mostra maior eficiência no seu uso, seguido por Espírito Santo, Minas Gerais e São Paulo.

\subsection{Transferências financeiras associadas à lucratividade (Transferências líquidas)}

Nos quatro Estados analisados, as transferências líquidas foram negativas: de $\mathrm{R} \$ 48,03, \mathrm{R} \$ 39,57, \mathrm{R} \$ 22,70$ e R \$1,81 por tonelada de celulose, em Minas Gerais, São Paulo, Espírito Santo e Bahia, respectivamente. Esses resultados indicam que as empresas tiveram seus lucros reduzidos, o que pode estar relacionado com taxações 
impostas à produção e comercialização da madeira de eucalipto e da celulose, apesar de serem Estados que operam com lucro.

Enquanto os maiores valores negativos foram observados na produção da celulose em Minas Gerais e em São Paulo, os menores valores negativos foram observados no Espírito Santo e na Bahia. Talvez, isso possa ser decorrente da maior taxação em Minas Gerais e em São Paulo e à menor taxação no Espírito Santo e na Bahia.

Verificou-se que Minas Gerais apresentou transferência maior, indicando que as empresas desse Estado foram mais penalizadas por políticas públicas distorcivas. Já a produção na Bahia apresentou a menor transferência líquida, indicando que as empresas do Estado foram menos penalizadas por políticas públicas distorcivas.

Outra característica que merece destaque é a distribuição do custo total entre custos comercializáveis e custos dos fatores domésticos a preço privado. Enquanto o Espírito Santo apresentou 85\% do custo total em forma do custo dos fatores domésticos, Minas Gerais, São Paulo e Bahia tiveram $84 \%$ de participação do custo dos fatores domésticos no custo total. Tal composição faz com que o Espírito Santo seja mais sensível às políticas governamentais em relação aos fatores domésticos.

A lucratividade privada é um indicador importante para que o produtor se sinta estimulado a produzir. Para que esse fato ocorra, é necessário que o governo proporcione melhores alternativas de políticas, como reduções nas taxações incidentes, tanto no produto quanto nos insumos usados na produção, que teriam como consequência o aumento da lucratividade e competitividade da celulose de fibra curta.

\subsection{Indicadores de competitividade privados e sociais}

Na Tabela 3, são apresentados os valores privados e sociais gerados pela MAP.

A produção na Bahia apresentou o menor RCP, indicando que nesse Estado a produção é mais competitiva entre os quatro analisados. Como a RCP é menor que um em todos os Estados analisados, considera-se que são lucrativos e remunerados acima do seu retorno normal.

Na Bahia, $87 \%$ do valor adicionado, ou seja, da diferença entre receita e custo dos insumos comercializáveis, a valores privados, é requerido para pagar os fatores domésticos e produzir uma tonelada a mais de celulose para o mercado interno. Raciocínio análogo pode ser feito para os demais Estados produtores. Em Minas Gerais, Espírito Santo e São Paulo, 92\%, 89\% e 89\% do valor adicionado a valores privados é requerido para pagar os fatores domésticos e produzir uma tonelada a mais de celulose, respectivamente (Tabela 3). Desse modo, as empresas podem manter os níveis de utilização dos fatores domésticos e expandir nessa atividade.

Como a maior competitividade da produção da celulose está na Bahia, esse estado apresenta a maior lucratividade e o maior potencial de expansão da produção.

Os CRDs inferiores a um nos diferentes Estados indicam eficiência da produção e competitividade, pois foram gastos $\mathrm{R} \$ 0,88, \mathrm{R} \$ 0,86, \mathrm{R} \$ 0,87$ e $\mathrm{R} \$ 0,86 \mathrm{em}$ recursos domésticos para gerar $\mathrm{R} \$ 1,00$ de divisas por meio de exportação em Minas Gerais, São Paulo, Espírito Santo e Bahia, respectivamente. Isso mostra a vantagem competitiva do Brasil nas exportações de celulose. Então, pode-se inferir que a expansão dessa atividade representa ganhos líquidos na alocação de recursos escassos.

Tabela 3 - Indicadores de competitividade privados e sociais gerados pela MAP.

Table 3 - Private and social competitiveness indicators generated by the PAM.

\begin{tabular}{ccccc}
\hline Indicadores & Minas Gerais & São Paulo & Espírito Santo & Bahia \\
\hline RCP & 0,92 & 0,89 & 0,89 & 0,87 \\
CRD & 0,88 & 0,86 & 0,87 & 0,86 \\
CPN & 0,95 & 0,96 & 0,97 & 0,96 \\
CPNp & 0,95 & 0,96 & 0,97 & 0,96 \\
CPNi & 0,69 & 0,68 & 0,68 & 0,67 \\
CPE & 1,00 & 1,02 & 1,03 & 1,02 \\
CL & 0,65 & 0,76 & 0,85 & 0,99 \\
TSP & $-0,04$ & $-0,03$ & $-0,02$ & $-0,001$ \\
\hline
\end{tabular}

Fonte: Dados da Pesquisa.

Cerne, Lavras, v. 19, n. 2, p. 297-305, abr./jun. 2013 
Os CPNps foram da ordem de 0,95 para Minas Gerais, 0,96 para São Paulo e Bahia e 0,97 para o Espírito Santo. Como os valores encontrados foram menores que um, há desproteção à atividade, uma vez que a empresa de celulose recebe um preço interno menor que o internacional. Além disso, esses resultados indicam que existem taxações implícitas sobre os sistemas de produção da celulose resultantes das medidas de políticas, uma vez que seus preços se encontram abaixo dos internacionais, o que levou as empresas de Minas Gerais, São Paulo, Espírito Santo e Bahia, a receber 5\%, 4\%, 4\% e 3\% menos do que os preços praticados no mercado internacional (Tabela 3).

Como os resultados encontrados para o CNPi foram menores que um em todos os Estados analisados, observouse que há transferência positiva de 31\%, 32\%, 32\% e 33\% em Minas Gerais, São Paulo, Espírito Santo e Bahia, respectivamente. Os custos dos insumos comercializáveis são bem menores no Brasil, principalmente o custo dos produtos químicos e da mão de obra, e não foram aumentados por intervenção política (Tabela 3).

Os CPEs para Minas Gerais, São Paulo, Espírito Santo e Bahia foram, respectivamente, 1,00, 1,02, 1,03 e 1,02. Esses valores maiores que um não indicam, necessariamente, baixa desproteção ou taxação no segmento produtivo de celulose, mas, sim, baixo custo dos produtos químicos e da mão de obra no Brasil (Tabela 3).

Deve-se ressaltar também que o CPE apresenta como limitação o fato de não incorporar os efeitos de políticas que influenciam os preços dos fatores domésticos, mas apenas de políticas que afetam os preços dos insumos comercializáveis. Dessa forma, pode-se considerar o CPE, como um indicador parcial dos efeitos dos incentivos das políticas, e não como um indicador completo. Para superar essa limitação, lança-se mão do Coeficiente de Lucratividade. Esse é considerado um indicador completo de incentivos, por considerar os efeitos das transferências políticas nos mercados de fatores, medindo o efeito de todas as políticas (FERREIRA NETO, 2005).

Os CLs encontrados foram menores que um e variaram de 0,65 a 0,99 , o que indica que a produção da celulose no Brasil foi liquidamente taxada e que o lucro privado se reduziu. Indica, também, desproteção total à produção de celulose no país. Ressalta-se, ainda, que em Minas Gerais a produção está mais desprotegida. O contrário pode-se afirmar do Estado da Bahia (Tabela 3).

Cerne, Lavras, v. 19, n. 2, p. 297-305, abr./jun. 2013
A TSP indica que os quatro Estados analisados sofreram alguma taxação por apresentarem valores negativos. Minas Gerais, São Paulo, Espírito Santo e Bahia foram taxados ou tiveram suas receitas reduzidas, respectivamente, em $4 \%, 3 \%, 2 \%$ e $0,2 \%$ (Tabela 3 ). Isso pode ser comprovado com base nos dados apresentados na Tabela 3, onde se encontra o valor dos impostos pagos pelas empresas do segmento de celulose e papel, em Minas Gerais, São Paulo, Espírito Santo e Bahia, em 2008.

Os valores da TSP indicam, ainda, que a produção de Minas Gerais, São Paulo, Espírito Santo e Bahia necessitariam, respectivamente, de $4 \%, 3 \%, 2 \%$ e $0,1 \%$ de subsídio, a fim de manter a mesma renda. Esses subsídios ocorreriam porque nesses Estados, as empresas de celulose receberam abaixo do que deveriam.

\section{CONCLUSÕES}

Conclui-se que a lucratividade privada da produção e comercialização de celulose foi positiva em todos os Estados analisados e maior na Bahia. Já, a lucratividade social foi maior em São Paulo. Além disso, a produção em na Bahia foi mais competitiva e menos exposta aos efeitos negativos das políticas públicas.

Em Minas Gerais, a produção de celulose foi mais penalizada por políticas públicas distorcivas e no Espírito Santo, observou-se maior sensibilidade da produção de celulose em relação a essas políticas sobre os fatores domésticos.

Verificou-se que a produção da celulose no Brasil vem sofrendo com a implantação de políticas públicas distorcivas, mas, mesmo assim, é lucrativa e competitiva. Do contrário, as empresas brasileiras poderiam ter alcançado níveis mais altos de lucratividade e competitividade.

\section{AGRADECIMENTOS}

A Universidade Federal de Viçosa e ao Conselho Nacional de Desenvolvimento Científico e Tecnológico $(\mathrm{CNPq})$, pela bolsa de doutorado para a primeira autora.

\section{REFERÊNCIAS}

ALVES, J. M. Competitividade e tendência da produção de manga para exportação do nordeste do Brasil. 2002. $163 \mathrm{f}$. Tese (Doutorado em Economia Aplicada) - Escola Superior de Agricultura “Luiz de Queiroz”, Piracicaba, 2002.

ANUÁRIO estatístico da agricultura brasileira. São Paulo: FNP Consultoria e Comércio, 2008. 
ARACRUZ CELULOSE. Relatório de sustentabilidade. Disponível em: <http://www.aracruz.com.br>. Acesso em: 1 abr. 2009.

ASSOCIAÇÃO BRASILEIRA DE CELULOSE E PAPEL. Relatório anual: 2009/2010. Disponível em: <http://www. bracelpa.org.br>. Acesso em: 11 set. 2012.

BAIER, J. C. V.; PÉRRAMON, J. A. C. Análisis económico de opciones productivas para plantaciones de Eucalyptus nitens en el sur de Chile. Disponível em: $<$ http:/www.chilenoticias. cl/revista_cifor/textos/e_nitens.pdf $>$. Acesso em: 20 maio 2008.

CARVAlHO, K. H. A.; COSTA, C. C. M.; SOARES, N. S.; SILVA, M. L. da. Desempenho das exportações brasileiras de papel. Scientia Florestalis, Piracicaba, v. 38, n. 86, p. 263-271, jun. 2010.

CARVAlHO, K. H. A.; SILVA, M. L. da; SOARES, N. S. Competitiveness of Brazilian wood pulp in the international market. Cerne, Lavras, v. 15, n. 4, p. 383-390, out./dez. 2009.

CELULOSE E PAPEL. Expansão: em 10 anos, setor investirá US\$13,3 Bi para dobrar produção. Celulose e Papel, São Paulo, n. 50 , p. $6-7,1995$.

CELULOSE NIPO BRASILEIRA. Relatório anual. Disponível em: <http://www.cenibra.com.br>. Acesso em: 1 abr. 2009.

CENTRO DE DESENVOLVIMENTO DO AGRONEGÓCIO. Coeficientes técnicos. Disponível em: $<$ http://www.cedagro.org. br>. Acesso em: 14 jun. 2008.

FERREIRA NETO, J. Competitividade da produção de cana-deaçúcar no Brasil. 2005. 87 f. Dissertação (Mestrado em Economia Aplicada) - Universidade Federal de Viçosa, Viçosa, 2005.

FOOD AND AGRICULTURE ORGANIZATION OF THE UNITED NATIONS. Statistic. Disponível em: $<$ http//:www. fao.org>. Acesso em: 23 abr. 2009.

INSTITUTO DE PESQUISA ECONÔMICA APLICADA. IPEADATA. Disponível em: $<$ http//:www.ipea.gov.br $>$. Acesso em: 13 jun. 2008.

MEDEIROS, V. X.; FONTES, R. M. O. Competitividade das exportações brasileiras de celulose no mercado internacional. Revista de Economia e Sociologia Rural, Brasília, v. 32, n. 2, p. 105-121, 1994.
MONKE, A. E.; PEARSON, S. R. The policy analysis matrix for agricultural development. New York: Cornell University, 1989. $278 \mathrm{p}$.

ROSADO, P. L.; TOSTO, S. G.; GOMES, M. F. M. Competitividade e expansão da produção de borracha natural brasileira, no contexto de liberalização dos mercados. In: ALVARENGA, A. P.; ROSADO, P. L.; CARMO, C. A. F. S. de; TOSTO, S. G. (Ed.). Seringueira: aspectos econômicos sociais e perspectivas para o seu fortalecimento. Viçosa, MG: UFV, 2006. p. 103-128.

SILVA, M. L. Análise econométrica do mercado brasileiro de celulose e de papel e papelão. 1996. 120 f. Tese (Doutorado em Ciência Florestal) - Universidade Federal de Viçosa, Viçosa, MG, 1996.

SOARES, N. S.; SILVA, M. L. da; LIMA, J. E. A função de produção da indústria brasileira de celulose, em 2004. Revista Árvore, Viçosa, v. 31, n. 3, p. 495-502, maio/jun. 2007.

SOUSA, E. P.; SOARES, N. S.; CORDEIRO, S. A.; SILVA, M. L. da. Competitividade da produção de palmito de pupunha no Espírito Santo e em São Paulo. In: ENCONTRO NACIONAL DE ESTUDOS REGIONAIS E URBANOS, 7., 2009, São Paulo. Anais... São Paulo: USP, 2009a. 1 CD-ROM.

SOUSA, E. P.; SOARES, N. S.; CORDEIRO, S. A.; SILVA, M. L. da. Competitividade da produção de palmito de pupunha (Bactris Gasipaes Kunth.) no Brasil. In: CONGRESSO DA SOCIEDADE BRASILEIRA DE ECONOMIA, ADMINISTRAÇÃO E SOCIOLOGIA RURAL, 47., 2009, Porto Alegre. Anais... Porto Alegre: SOBER, 2009b. 1 CD-ROM.

VALVERDE, S. R.; SOARES, N. S.; SILVA, M. L. da. Desempenho das exportações brasileiras de celulose. Revista Árvore, Viçosa, v. 30, n. 6, p. 1017-1023, nov./dez. 2006.

VERACEL CELULOSE. Relatório anual. Disponível em: $<$ http://www.veracel.com.br>. Acesso em: 24 abr. 2009.

VIEIRA, R. C. M. T.; TEIXEIRA FILHO, A. R.; OLIVEIRA, A. J. de; LOPES, M. R. Cadeias produtivas no Brasil: análise da competitividade. Revista de Política Agrícola, Brasília, ano 10, n. 4 , p. $7-15$, out./dez. 2001

VOTORANTIN CELULOSE E PAPEL. Relatório anual. Disponível em: <http://www.vcp.com.br>. Acesso em: 1 abr. 2009.

Cerne, Lavras, v. 19, n. 2, p. 297-305, abr./jun. 2013 
